\title{
Experimental Organism Neoplasm
}

National Cancer Institute

\section{Source}

National Cancer Institute. Experimental Organism Neoplasm. NCI Thesaurus. Code C134576.

A neoplastic condition that is relevant to either disease states or models of disease in experimental organisms. 